\title{
MODIFICACIONES CRANEALES PARACAS: ¿ESTATUS, ETNICIDAD, ESTÉTICA?
}

\author{
Elsa Tomasto-Cagigao ${ }^{a}$
}

\begin{abstract}
Resumen
Uno de los aspectos que más llamó la atención de los arqueólogos desde las primeras exploraciones de la peninsula de Paracas, a inicios del siglo XX, fueron las modificaciones craneales. Desde entonces hasta la fecha, se han realizado numerosas descripciones y clasificaciones, y se han propuesto diversas hipótesis referentes a las razones que estarian detrás de esta práctica cultural: estatus, género, origen, etnicidad, etc., elementos todos de la identidad. Sin embargo, todavía no se ha podido validar ninguna de estas hipótesis, porque no existe ningún estudio sistemático que haya clasificado las formas craneales y las haya relacionado con las características de los contextos de procedencia. En el marco del creciente interés por conocer la dinámica social y politica de finales del Periodo Formativo en la costa sur del Perú, la identidad de las personas enterradas en los cementerios de la peninsula de Paracas y su posible relación con poblaciones que habitaban los valles hacia el norte y hacia el sur, es un tema de discusión central, que ha sido abordado principalmente a partir del estudio de los objetos asociados a los enterramientos. En este contexto, el estudio de las modificaciones craneales adquiere relevancia, más aun considerando que los estudios genéticos no han logrado un nivel de resolución fino en el caso de Paracas. En este artículo, se estudia y clasifica las formas craneales de 38 individuos procedentes de 35 contextos funerarios paracas, excavados en el cementerio de Wari Kayán y en los valles de Palpa. Tratándose de una muestra pequeña y no aleatoria, este estudio no pretende dar una respuesta definitiva a las posibles razones detrás de esta práctica en el mundo Paracas. Por el contrario, el objetivo es abrir el camino para la inclusión de este tipo de estudios en la discusión, mostrando su potencialidad y presentando una propuesta de clasificación que nos ha permitido diferenciar tres grupos de individuos: aquellos enterrados en la peninsula de Paracas que estaban asociados a textiles del Horizonte Temprano, los que estaban asociados a textiles del Intermedio Temprano y los que proceden de los valles sureños.
\end{abstract}

Palabras clave: modificaciones corporales, identidad, bioarqueología

\section{Abstract}

\section{PARACAS’ CRANIAL MODIFICATIONS: STATUS, ETHNICITY AND AESTHETIC?}

Since the first explorations at the Paracas Peninsula in the beginnings of the 20th Century, cranial modifications drew attention of archaeologists. Several descriptions and classifications have been proposed, as well as hypothesis regarding the reasons behind this cultural practice; generally elements of identity such as status, gender, origin and ethnicity. Nevertheless, none of these hypothesis have been demonstrated yet, since there are not systematic studies correlating cranial shapes with archaeological provenience. In the context of the increasing interest regarding the Late Formative social and political dynamics in the South Coast of Peru, the identity of people buried in the Paracas Peninsula cemeteries and their possible relations to populations that inhabited the valleys towards the north and south is a central issue that has been addressed from the study of objects associated to the burials. Nevertheless the study of human remains is crucial and since the DNA preservation in coastal archaeological context is not good, the study of cranial modifications can give important information. In this paper we study and classify the cranial shapes of 38 individuals coming from 35 Paracas mortuary contexts that were excavated at Wari Kayan and at the Palpa valleys. As this sample is non-random and small, this study cannot to give a final answer to the possible reasons behind this practice in the Paracas realm, but it opens the discussion of this type of evidence, showing its potential and proposing a classification that allowed us to differentiate three groups of individuals: Those buried at the Peninsula and associated to Early Horizon textiles, those associated to Early Intermediate textiles and those coming from the southern valleys.

Keywords: body modifications, identity, bioarchaeology

\footnotetext{
a Departamento de Humanidades, Pontificia Universidad Católica del Perú Correo electrónico: etomast@pucp.edu.pe
} 


\section{La práctica de la modificación craneal}

El rostro y la cabeza, como parte más visible de la persona, son elementos centrales en la construcción y expresión de la identidad. A lo largo de la historia, diferentes pueblos han utilizado este segmento del cuerpo de muy distintas maneras para expresar variados significados. Existen formas temporales de cambiar el aspecto del rostro y la cabeza, tales como los peinados, los tocados y la pintura facial. Existen también formas permanentes, como el tatuaje, la escarificación, y la perforación de la piel y los cartílagos para colocar en ellos elementos de adorno. Pero, la modalidad más drástica de modificación del aspecto de la cabeza es la remodelación craneal. Esta práctica consiste en la colocación de elementos rígidos (tablillas) y/o flexibles (almohadillas de diferentes formas, cintas, correas) que se ajustan cuidadosamente al cráneo en crecimiento y producen presión en ciertas zonas; de esta manera, dirigen el crecimiento hacia las áreas del cráneo donde existe menor presión (Tiesler 2014).

Este procedimiento solo puede realizarse durante los primeros meses de vida y hasta los tres años de edad, es decir, cuando los tejidos del cráneo son flexibles y durante la etapa en la cual el crecimiento del cerebro es muy rápido. Al momento de nacer, la cabeza del feto debe amoldarse a la forma del canal del parto. Por ello, los huesos son flexibles y las articulaciones entre ellos están compuestas de membranas y tejido fibroso, tanto en las suturas como en las fontanelas. Poco después del nacimiento, algunas fontanelas se cierran, pero la flexibilidad de los tejidos que componen el cráneo continúa durante la rápida expansión del cerebro, que alcanza el 50 por ciento de su tamańo hacia los seis meses después del nacimiento; y el 75 por ciento, hacia los dos años de edad. Después de ello, el cerebro sigue creciendo, pero a un ritmo mucho más lento, hasta alcanzar la totalidad de su desarrollo hacia los 10 años (Scheuer y Black 2000: 43). En esta última etapa, si bien los huesos siguen acompañando el crecimiento del cerebro, no tienen la maleabilidad de los años anteriores.

Tiesler (2014) expone con detalle la complejidad de la ejecución de las modificaciones craneales; al respecto, explica que la cabeza manipulada del infante es una unidad funcional viva que se va ajustando a tensiones mecánicas intrínsecas, producidas por el desarrollo natural, y extrínsecas, ejercidas por los aparatos deformadores. En este proceso, el crecimiento activo corresponde al cerebro, mientras que el comportamiento de los huesos es una respuesta a la expansión neural. Así, los huesos planos de la bóveda craneal van modificando su forma tanto en su parte central como en sus márgenes para permitir que el crecimiento se dé de una manera equilibrada a lo largo de las suturas y fontanelas. Esto implica que la reabsorción y aposición de hueso deben darse de manera coordinada en todas las regiones de todos los huesos. En este contexto, las tensiones locales producidas por los elementos rígidos y flexibles de los aparatos deformadores son biológicamente asimiladas, creándose fuerzas compensatorias que reorientan el crecimiento de los huesos hacia las zonas con menor presión. Esto resulta en la modificación de la forma de todos los huesos de la cabeza, incluidos los huesos de la cara y la base del cráneo, que son áreas en las que no actuaron directamente los aparatos deformadores (Anton 1989; Deshayes 2005; Jiménez 2011; Tiesler 2014).

En la medida en que la modificación craneal estuvo ampliamente extendida en el mundo, tanto en tiempo como en espacio, existen numerosos estudios que van desde lo descriptivo y tipológico hasta lo antropológico, buscando los correlatos culturales de esta costumbre, y lo biológico, centrándose en aspectos evolutivos y de desarrollo. Tanto Blom (1999), como Hoshower et al., (1995), Tiesler (2014) y Torres-Rouff (2003) exponen extensamente la variedad de estudios realizados a nivel mundial en referencia a esta práctica.

En las culturas andinas, la modificación de la forma del cráneo estuvo íntimamente vinculada con el uso de peinados y tocados que permitían la identificación de personas de distintos orígenes geográficos o sociales. Esto fue referido y descrito por muchos de los primeros cronistas y varios autores presentan recuentos detallados de estas referencias (Weiss 1961; Allison et al. 1981; Blom 1999; Hoshower et al. 1995; Zabala 2014). Por otra parte, la práctica estuvo en uso hasta avanzado el siglo XX entre grupos nativos de la Amazonía, lo cual ha sido registrado también por diversos 
autores (c.f. Reichlen 1961; Tommaseo y Drusini 1984). En estos escritos, se abordan varios aspectos de la modificación craneal, como las diferencias en las formas logradas y los tipos de prendas de cabeza que se usaban en asociación con ellas, detalles de los aparatos deformadores empleados y las razones que daban los usuarios de esta práctica para su ejercicio. También, se ensayan diversas tipologías que se basan en las formas de las cabezas, en los tipos de aparatos utilizados o en una combinación de ambos criterios, y que proponen desde dos hasta 16 tipos (Blom 1999).

Entre las alteraciones de las formas craneales que describen los cronistas, están las frentes ensanchadas; «quebrantadas» (¿hundidas?) o adelgazadas; las nucas aplastadas o ensanchadas; y las cabezas alargadas, que, en algunos casos, adquieren la forma de un mortero. En cuanto a las razones que se aducen para la modificación de la cabeza, son muy variadas. La identificación de la región de origen es señalada por varios cronistas y recogida por los autores previamente mencionados (Weiss 1961; Torres-Rouff 2003), pero también se citan aspectos como la diferenciación de etnias; el establecimiento de fronteras sociales-estatus (Torres-Rouff 2003; Zabala 2014); el deseo de asemejarse a algún elemento de la naturaleza como el sol (Reichlen 1961), la luna llena o los volcanes; el influir en aspectos de la conducta como la obediencia, la valentía, la fuerza o la capacidad de trabajar; el lucir una apariencia fiera (Zabala 2014); o simplemente razones prácticas, como el evitar que los cabellos cubran los ojos (Reichlen 1961).

Ante esta variedad de motivos, Torres-Rouff (2003) cita varios estudios recientes que demuestran que las razones y las implicancias sociales de la modificación craneal son específicas de cada cultura. En cualquier caso, es importante considerar que, sean cuales fueren las razones detrás de esta costumbre, estas tenían que estar muy fuertemente arraigadas en la sociedad y ser muy estables, puesto que, una vez realizada la modificación de la forma del cráneo, no hay vuelta atrás y la persona deberá llevarla de por vida. Así mismo, en la decisión de realizar o no la modificación craneal, no participa el individuo que es objeto de la práctica y, por tanto, en ella se expresan elementos del estatus adscrito. Al respecto, Zabala (2014) resalta la referencia recogida por Molina, el Cusqueño, (1947 [1573]) en relación con una ceremonia denominada Ayuscay, que formaba parte de los rituales alrededor el nacimiento de los nińos en la sociedad incaica y que consistía en la colocación del recién nacido en la cuna, artefacto que en varias sociedades prehispánicas servía también como aparato deformador. Este evento ocurría al cuarto día de nacimiento del niño y con la participación de todos los parientes.

\section{Antecedentes de estudios de modificaciones craneales paracas}

En el contexto andino, Paracas es uno de los grupos humanos que más atención ha recibido en referencia con las modificaciones corporales en general (Aponte 2013; Tomasto-Cagigao 2013; Tomasto-Cagigao et al. 2013; Maita y Minaya 2014) y a las modificaciones craneales en particular, puesto que estas son en muchos casos extremas, y la preservación de los tocados y peinados es excepcional. De esta manera, se han realizado varias descripciones y clasificaciones (Weiss 1961; Yépez 2006; Dausse 2015), ${ }^{1}$ así como estudios de orientación más bien biológica o médica (c.f. Bolender et al. 1978; Deshayes 2005).

El primero en describir y clasificar los cráneos paracas fue Pedro Weiss, quien fue pionero en plantear una aproximación que hoy es la base de los estudios bioarqueológicos: la necesidad de estudiar los restos humanos en asociación con «la época, la región geográfica y rastreando las posibles asociaciones con otros caracteres» (Weiss 1961: I), es decir, todo lo que en arqueología se conoce hoy como información contextual. En este sentido, Weiss plantea que las remodelaciones craneales no pueden ser descritas simplemente como una forma geométrica, sino que para realizar una tipología de modificaciones craneales se deben tener en cuenta aspectos como la cultura, región, aparatos deformadores, representaciones artísticas de modificaciones craneales, patologías y prácticas terapéuticas asociadas. 
Siguiendo esta aproximación, Weiss clasificó las modificaciones craneales peruanas precolombinas en 12 tipos distribuidos en tres grupos, uno de los cuales está dividido a su vez en dos subgrupos (Weiss 1961: 19-21). Los cráneos modificados paracas fueron clasificados dentro del segundo grupo: modificaciones producidas por vendajes circulares o llautu, y en el subgrupo denominado Paracas-Nasca. Este subgrupo, que reúne cinco tipos, se define por el uso de roscas o almohadillas localizadas en distintos puntos del cráneo, generalmente, en el occipital y/o frontal, además de los amarres circulares. Según Weiss, el uso de aperos con esta combinación de elementos dio a las modificaciones craneales de este subgrupo una apariencia que reúne rasgos característicos de las modificaciones circulares, de las tabulares y de las seudo tabulares de Imbelloni (Imbelloni 1925; Dembo e Imbelloni 1938).

Los tipos dentro de cada subgrupo fueron bautizados con nombres que hacen referencia a las culturas en las que determinada forma de cráneo aparece con mayor frecuencia. De esta manera, dentro del subgrupo Paracas-Nasca, se encuentran los tipos Cavernas, Necrópolis, Cabeza Larga, Natchez y Nasca (Weiss 1961: láms. XX, XXII, XXIII, XXV, XXVII). Al tratar de replicar la tipología de Weiss en nuestro análisis de los materiales de la península, encontramos que sus descripciones de los tipos generales de modificación son muy acertadas, pero la confusión surge cuando se agregan variantes dentro de cada tipo, cuyos límites no son siempre claros: existen formas intermedias difíciles de categorizar al punto de poder confundirse con otros tipos. Por otra parte, el uso de nombres de sitios, culturas o fases para los tipos añade elementos semánticos que resultan confusos.

En un estudio más reciente, Yépez (2006) propone una nomenclatura diferente usando criterios de Weiss y de Imbelloni. En términos generales, llama «anular» a la deformación aymara de Weiss; tabular cilíndrica, a la Necrópolis; y cuneiforme, a la Cavernas. Además, encuentra una serie de subtipos o variantes basadas en detalles, como la inclinación del frontal y la forma del vértex del cráneo (Yépez 2006: 391 y siguientes). La definición de los tipos propuestos por Yépez es más sencilla y directa que la de Weiss, y el uso de términos descriptivos contribuye a esta claridad. Sin embargo, sus subtipos son confusos y persiste el problema de las formas intermedias entre un tipo y otro. A ello se debe añadir que la muestra consiste en 39 cráneos, de los cuales por lo menos 20 no tienen contexto.

La necesidad de crear tipos, subtipos y variantes en ambas clasificaciones describe perfectamente la variedad de formas craneales que se encuentran en la península. Sin embargo, al no considerar la información contextual completa de cada cráneo clasificado (procedencia, tumba, fardo, objetos asociados, localización en el cementerio, otros contextos funerarios cercanos o similares), ninguna de estas tipologías puede responder a la pregunta de las razones que, en el mundo paracas, justificarían esta práctica, ni tampoco contribuir al conocimiento de quienes estarían enterrados en la península de Paracas y qué relación podrían tener con otras poblaciones identificadas como Paracas en los valles localizados hacia el norte o hacia el sur. Considerando que dicha península posiblemente fue un centro de convergencia y negociación entre las sociedades que habitaron la costa sur a finales del Período Formativo y, más específicamente, entre sociedades sureñas de posible tradición Paracas y sociedades norteñas de posible tradición Topará (Tomasto-Cagigao y Peters [eds.] e.p.), el estudio de las modificaciones craneales, en conjunto con las características de los contextos mortuorios en que fueron hallados los individuos que las lucían, podría ayudar a comprender la dinámica social y política de esta época de cambios políticos, fuerte interacción social y movimientos poblacionales. $\mathrm{Al}$ respecto, cabe señalar que, en un estudio de $\mathrm{ADN}$ mitocondrial de 46 individuos paracas procedentes de la península, de los valles de Palpa y del valle de Cañete, se concluyó que las poblaciones de las tres áreas estaban biológicamente relacionadas; no existía una distancia genética significativa entre ellas por el lado materno (Fehren-Schmitz y Tomasto-Cagigao 2012). En este contexto, y considerando el bajo nivel de conservación de $\mathrm{ADN}$ nuclear en muestras prehispánicas de la costa central (Fehren-Schmitz et al. 2013), no es posible esperar una mayor resolución a nivel genético. Por tanto, las modificaciones craneales constituyen una de las pocas fuentes que, desde el estudio de los restos humanos, pueden contribuir a responder a la pregunta de quiénes fueron las personas enterradas en la península de Paracas y qué relaciones tendrían con las poblaciones vecinas. 


\section{Materiales y metodología}

El estudio que presentamos en este artículo está basado en la revisión de 35 contextos mortuorios paracas, que contenían 38 individuos, de los cuales 21 proceden de la Necrópolis de Wari Kayán; y 17 de los sitios, Pernil Alto, Jauranga, Pinchango Alto, Collanco y Estaquería, ubicados en los valles de Palpa (Tablas 1 y 2, Fig. 1). El sexo y la edad de estos individuos fueron establecidos utilizando los métodos tradicionalmente empleados para la reconstrucción del perfil biológico en individuos esqueletizados (Phenice 1969; Iscan et al. 1984; Lovejoy et al. 1985; Iscan y Loth 1986; Suchey 1986; Buikstra y Ubelaker 1994; Scheuer y Black 2000; DiGangi et al. 2009).

La mayoría de los individuos procedentes de Wari Kayán fueron estudiados como parte del proyecto de investigación «Prácticas en vida, presencia después de la muerte: lo estilístico y lo material en Paracas Necrópolis», bajo la dirección de Ann Peters y la autora. Solo uno de los individuos fue estudiado en el marco del proyecto «Fardo funerario paracas 298: Investigación y puesta en valor». La selección de estos contextos mortuorios no fue aleatoria, sino que dependió de la accesibilidad a los materiales en cada uno de los museos que los custodian. Respecto a este punto, hay que tener en cuenta que, en Wari Kayán, los individuos fueron inhumados al interior de fardos, lo cual implica que para tener acceso a los restos humanos es necesario que los fardos hayan sido previamente abiertos. Los procesos de apertura de fardos funerarios como los de Wari Kayán son complejos y solo un 32 por ciento de los 429 fardos excavados por Tello en la Necrópolis han sido abiertos a la fecha (Tomasto-Cagigao et al. 2016). En estas aperturas, se ha privilegiado los fardos más grandes y mejor conservados, o que presentaban textiles vistosos en el exterior; de hecho, Tello y su equipo los seleccionaron desde el mismo momento de la excavación (Tello y Mejía Xesspe 1979). Los fardos de estas características contenían en su mayoría individuos de sexo masculino y de mediana edad (Tomasto-Cagigao et al. 2016). De esta manera, en la muestra estudiada en el marco de esta investigación, se refleja este sesgo, al estar compuesta solo por adultos, de los cuales 17 son masculinos y solo cuatro, femeninos (Tabla 1).

La preservación de los restos humanos procedentes de Wari Kayán es variable. En general, los huesos se han conservado bien, aunque suele haber zonas de hueso esponjoso deteriorado o superficies erosionadas en el esqueleto poscraneal. La preservación de materiales orgánicos es mucho más variable y, en el caso de los cráneos, es muy frecuente encontrar restos de cabello, que, muchas veces, preservan el peinado o inclusive parte del tocado. Para los fines de esta investigación, esto fue una desventaja, porque el cabello y los elementos del tocado impidieron registrar directamente las huellas dejadas en el hueso por los aparatos deformadores (véase más adelante). Por este motivo, fue necesario realizar un registro radiográfico, ${ }^{2}$ el cual dependió de la posibilidad de acceder a los equipos necesarios en cada museo (Tabla 1).

La muestra de Wari Kayán fue dividida en dos grandes grupos, de acuerdo con los estilos predominantes entre las asociaciones textiles, identificados por Ann Peters (comunicación personal 2015). Además, se obtuvieron fechados de C14 de muestras de cabello de ocho individuos. De esta manera, 11 contextos fueron clasificados en la parte temprana de la secuencia, con textiles de las fases 10 A y B del Horizonte Temprano, y con fechados de 310 a 110 a. C. Ocho individuos fueron clasificados en la parte tardía de la secuencia, con textiles de las fases 1 y 2 del Intermedio Temprano, y con fechados entre 200 a C. y 10 d.C. En dos contextos, no hubo coincidencia entre el fechado y el estilo predominante en los textiles (Tabla 1). El fardo 364 tiene objetos de los estilos $10 \mathrm{~B}$ y $1 \mathrm{~A}$ y fechado de 370 a 240 a.C. Sin embargo, hay indicios de exposición al sol que sugieren que el paquete funerario fue destruido y reconstruido, por lo que, en este caso, consideramos que correspondería al grupo de contextos más tempranos. En el caso del fardo 97, solo se pudo examinar el tocado y se tienen referencias del estilo de un unku. Ante esta escasez de información, lo clasificamos en el grupo de fardos tardíos sobre la base del fechado.

Los 17 individuos procedentes de los valles de Palpa fueron excavados entre los años 1997 y 2013 en el marco de los proyectos de investigación «Nasca-Palpa» $\mathrm{y}$ «Palpa-Lucanas», dirigidos por Markus Reindel y Johny Isla. Si bien son más de 60 los contextos funerarios paracas excavados 


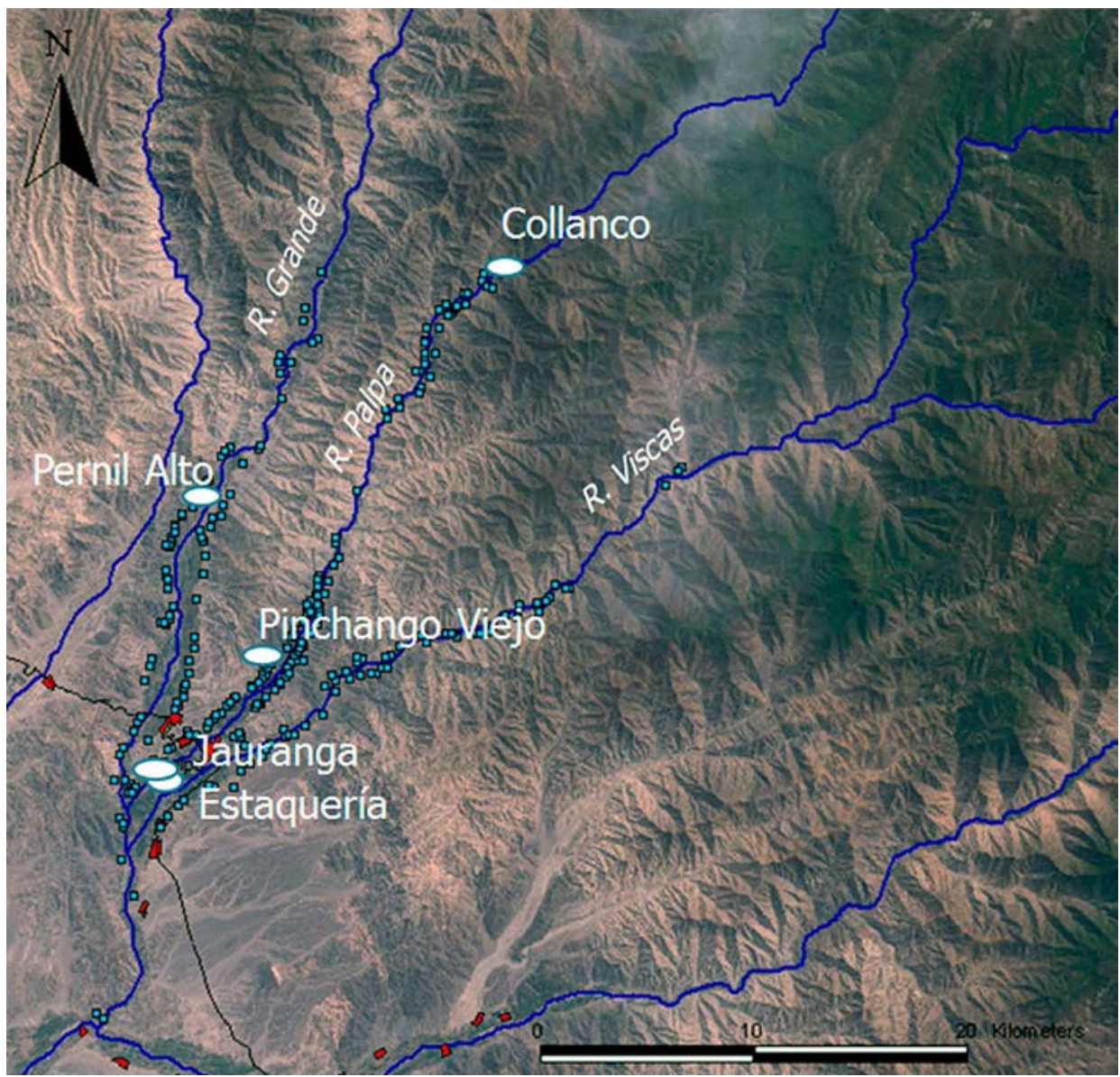

Figura 1. Sitios arqueológicos en los valles de Palpa de donde procede la muestra estudiada (Proyecto Nasca-Palpa).

por estos proyectos (Isla 2009; Tomasto-Cagigao et al. 2015), en este caso, la posibilidad de analizar las modificaciones craneales estuvo restringida por el estado de conservación de los huesos. La mayoría de contextos funerarios paracas excavados en los valles de Palpa proceden del sitio de Jauranga, el cual se ubica en tierras cultivables en el fondo del valle, rodeadas de bosquecillos de eucaliptos. La humedad del suelo y las raíces de los árboles afectaron severamente la conservación de los huesos, de manera que solo fue posible observar los cráneos que pudieron ser reconstruidos total o parcialmente. De este modo, en esta muestra, tres cráneos están completos y los demás han sido parcialmente reconstruidos. Sin embargo, en todos los cráneos reconstruidos, es posible observar la forma general de la bóveda (véase más adelante) y en la mayoría fue posible anotar también detalles de las huellas dejadas por los aparatos deformadores. Por otra parte, la distribución por sexo y edad es más equilibrada; existen seis cráneos de subadultos y 11 de adultos, de los cuales tres son femeninos, siete son masculinos o posiblemente masculinos, y uno es de sexo indeterminado (Tabla 2). De igual manera, están representadas todas las formas de estructura funeraria registradas en los valles de Palpa (Tomasto-Cagigao et al. 2015). Finalmente, en cuanto a la cronología, la mayoría de los cráneos analizados (11) corresponden a Paracas Tardío (Unkel et al. 2012); es decir, son contemporáneos con los fardos de las fases $10 \mathrm{~A}$ y $\mathrm{B}$ del Horizonte Temprano de la península, mientras que tres corresponden a Paracas Temprano, uno a Paracas Medio y dos al Período Transicional, contemporáneo con los fardos del Intermedio Temprano de la península (Tabla 2). 

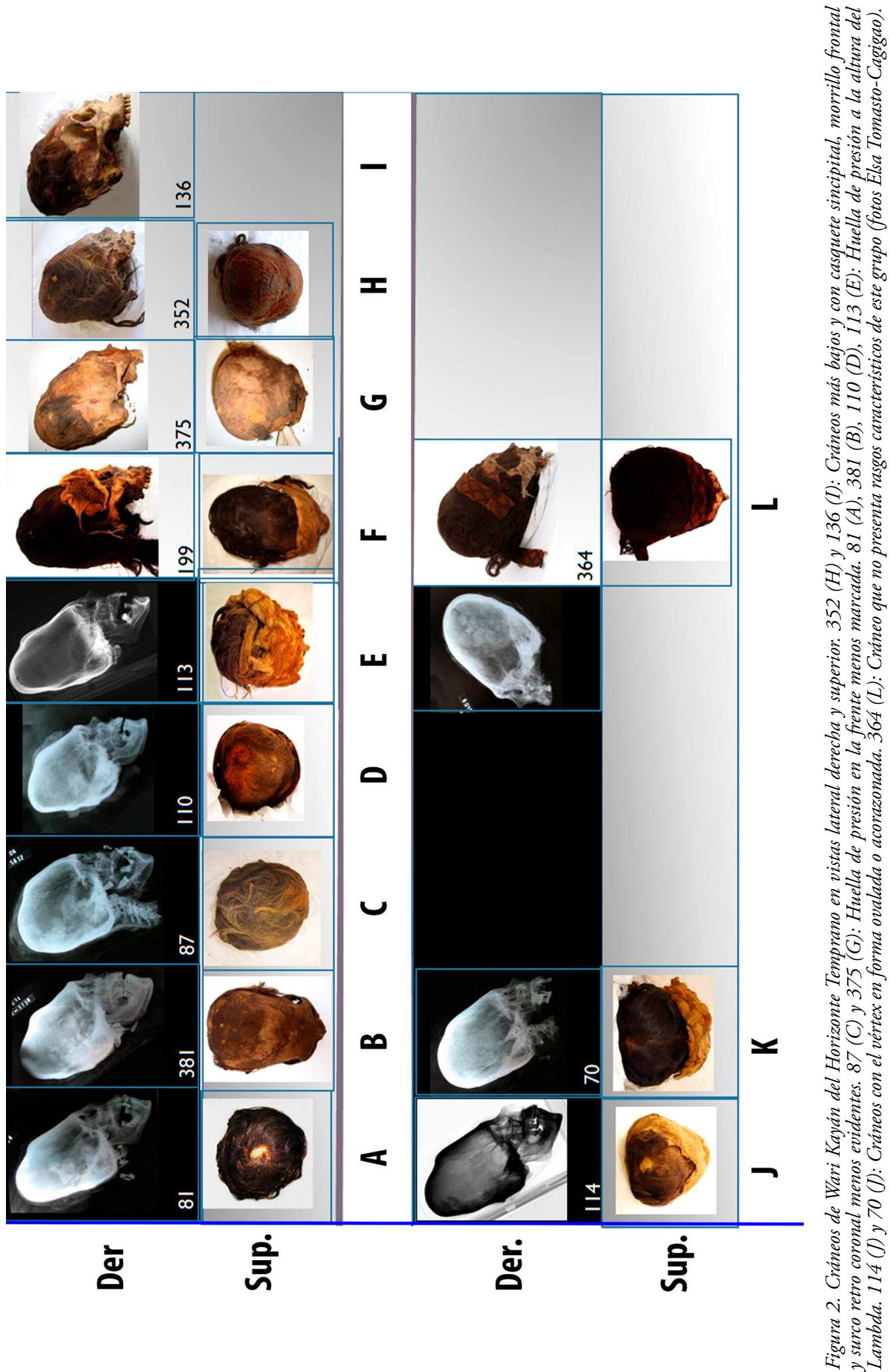
La metodología empleada para la clasificación de la forma de los cráneos fue establecida utilizando elementos de varias propuestas. Si bien para el estudio de las modificaciones craneales en los Andes se han planteado diversas tipologías, que van desde dos hasta 16 tipos (Blom 1999), en general, se tiende a privilegiar la propuesta de Imbelloni (Dembo e Imbelloni 1938), que divide el espectro de formas en dos grandes grupos: las anulares y las tabulares, que, a su vez, pueden ser erectas u oblicuas. Por su sencillez, esta tipología es adecuada para realizar comparaciones a gran escala. Por ejemplo, usando esta tipología, Blom (1999) y Torres-Rouff (2003) han podido brindar explicaciones bien sustentadas respecto al porqué del uso de la modificación craneal en los Andes centrosur durante el tiempo de influencia Tiwanaku y en los Andes en general a lo largo de la historia prehispánica. Sin embargo, al tratar de emplear esta tipología en estudios de menor escala, se tropieza con el problema de su baja resolución y se puede caer en el error de clasificar dos cráneos muy diferentes dentro de la misma categoría, como muy claramente notó Reichlen hace más de 50 años: «Así, desde el punto de vista más general de la clasificación de las deformaciones craneales, debemos admitir que el marco en el cual, siguiendo a Imbelloni, los antropólogos se esfuerzan en hacer encajar los cráneos deformados, es inadecuado. Toda observación minuciosa se encuentra con esta dificultad [...] Con términos tan vagos como "tabular" o "antero-posterior" y "circular"; y tan equívocos como "erecto" y "oblicuo", uno es llevado a agrupar piezas cuya historia e incluso cuyo aspecto son muy diferentes» (Reichlen 1961: 77). ${ }^{3}$

De igual manera, en su estudio de cráneos modificados peruanos, Weiss encontró la misma dificultad, como expresa en el párrafo siguiente: «En nuestro propósito de relacionar las formas con las culturas, siempre que quisimos trabajar con las tarjetas que habíamos confeccionado, tropezábamos con la insuficiencia de las nomenclaturas, para identificarlas. Ninguna fórmula taxonómica que no fuese una descripción completa o las fotografías y los gráficos, era suficiente por sí sola para distinguir un cráneo de Nasca de uno de la cultura Huaura, uno de Cavernas de los comunes de la Costa y así con otras formas que a la vista mostraban saltantes diferencias» (1961: 13).

Por otra parte, considerando las descripciones de los primeros cronistas de la variedad de formas de las cabezas y la mención de que cada una de las provincias principales tenía un modelo diferente de cabeza (véase Zabala 2014), una clasificación de solamente dos o tres tipos como la que propone Imbelloni resulta insuficiente. Finalmente, en un estudio de las formas de modificación craneal en uso en el área de Moquegua durante el tiempo de la influencia Tiwanaku, Hoshower et al. (1995) demostraron que el estudio de los detalles de las huellas de presión en los cráneos permitía identificar similitudes y diferencias dentro y entre cementerios, que de otra manera habrían pasado desapercibidas.

En la problemática relacionada con la dinámica social y política de finales del Período Formativo en la costa sur del Perú, interesa conocer tanto la composición de la población enterrada en la península de Paracas - aparentemente, un lugar de convergencia- como las características particulares de poblaciones de otras regiones en el ámbito paracas. En este sentido, son relevantes tanto las formas generales de las cabezas, que pudieron haber sido percibidas por otros como marcadores de identidad, como los detalles de las huellas de presión en los cráneos, que pueden hacer referencia a los métodos y acciones aceptados a nivel familiar o comunal para lograr las formas de cabeza deseadas. Sin embargo, en el registro de estos detalles, se debe tener en cuenta que existen variaciones individuales provocadas por posibles desajustes o desacomodos de los aperos durante los dos o tres ańos en que los niños debieron haberlos llevado puestos, y por la manera particular en que se cerraron las suturas o se desarrollaron las inserciones musculares durante el desarrollo de cada individuo una vez retirado el apero (Weiss 1962; Hjortsjö y Lindh 1947, citados en Blom 1999).

Con todas estas consideraciones en mente, se optó por registrar las huellas dejadas por los aparatos deformadores en las superficies de los huesos de la bóveda craneal y combinar esta aproximación con una clasificación de las formas, realizada sobre la base de las fotografías y las radiografías tomadas durante el trabajo de campo. Debido a la posible variabilidad debida al desarrollo particular de cada individuo, en ningún caso, hemos considerado grados en la manifestación de las huellas de los aperos, sino solamente su presencia o ausencia. A continuación, se explican los rasgos 


\begin{tabular}{|l|l|c|c|l|l|l|}
\hline Fardo & \multicolumn{1}{|c|}{ Sexo } & Categoría (Tello) & Estilo de textiles & \multicolumn{2}{|c|}{ Fechado } & \multicolumn{1}{|c|}{ Museo } \\
\hline 4 & Masculino & $\mathrm{X}$ & $1 \mathrm{~B}$ & Nasca inicial & 120 - 40 a.C & MNAAHP \\
\hline 16 & Masculino & $\mathrm{X}$ & $1 \mathrm{~A}$ & & & Peabody \\
\hline 23 & Masculino & $\mathrm{Z}$ & 2 & Nasca inicial & 200 - 100 a.C & MNAAHP \\
\hline 24 & Masculino & $\mathrm{Y}$ & $1 \mathrm{~A}$ & Nasca inicial & 160 - 60 a.C & MNAAHP \\
\hline 26 & Masculino & $\mathrm{Y}$ & $1 \mathrm{~A}$ & & & MNAAHP \\
\hline 27 & Masculino & $\mathrm{X}$ & $1 \mathrm{~B}$ & & & Inka \\
\hline 70 & Femenino & $\mathrm{Z}$ & $10 \mathrm{~A}$ & Paracas tardío & 310 - 210 a.C & MNAAHP \\
\hline 81 & Femenino & $\mathrm{Z}$ & $10 \mathrm{~A}$ & & & MNAAHP \\
\hline 87 & Femenino & $\mathrm{Z}$ & $10 \mathrm{~A}$ & Paracas tardío & $300-110$ a.C. & MNAAHP \\
\hline 97 & Masculino & $\mathrm{Z}$ & $10 \mathrm{~A}$ & Nasca inicial & $200-100$ a. C & MNAAHP \\
\hline 110 & Masculino & $\mathrm{Z}$ & $10 \mathrm{~A}$ & & & MNAAHP \\
\hline 113 & Femenino & $\mathrm{Z}$ & $10 \mathrm{~A}$ & & & NMNH \\
\hline 114 & Masculino & $\mathrm{Y}$ & $10 \mathrm{~A}$ & & & NMNH \\
\hline 136 & Masculino & $\mathrm{Z}$ & $10 \mathrm{~A}$ & & & MRI \\
\hline 188 & Masculino & $\mathrm{Z}$ & $1 \mathrm{~B}$ & & & NMNH \\
\hline 199 & Masculino & $\mathrm{Y}$ & $10 \mathrm{~A}$ & & & MNAAHP \\
\hline 298 & Masculino & $\mathrm{X}$ & 2 & Nasca inicial & 80 a.C - 10 d.C & MNAAHP \\
\hline 352 & Masculino & $\mathrm{X}$ & $10 \mathrm{~B}$ & & & MRI \\
\hline 364 & Masculino & $\mathrm{X}$ & $1 \mathrm{~A}$ & Paracas tardío & $370-240$ a.C & MNAAHP \\
\hline 375 & Masculino & $\mathrm{Y}$ & $10 \mathrm{~B}$ & & & Inka \\
\hline 381 & Masculino & $\mathrm{Z}$ & $10 \mathrm{~A}$ & & & MNAAHP \\
\hline
\end{tabular}

Tabla 1. Muestra de fardos de Wari Kayán.

que fueron registrados. Se hace referencia a ejemplos de esta colección que presentan los rasgos más marcados y se citan los autores que han empleado anteriormente los rasgos.

Forma general de la bóveda: Se refiere a su aspecto general, que podría haber sido fácilmente percibido y diferenciado por otras personas: alta o baja, percibida en una vista lateral ( $v . g$. Figs. 3 y 6 , vistas laterales en la fila superior); ancha o angosta percibida en las vistas anterior, posterior o superior (v.g. Fig. 2A y 2K, fila inferior) (eje de la forma y diámetros horizontales de Weiss 1961; bóveda alta o baja de Allison et al. 1981).

Respecto a este rasgo, es importante considerar también que, ante la presión de los aparatos deformadores, no solo se modifica la forma de las zonas bajo presión, sino del cráneo en su conjunto. De esta manera, las fisonomías de las personas con cráneos extremadamente alargados se caracterizan por tener rasgos saltones, mientras que rasgos faciales aplanados suelen ser característicos de cráneos con modificación antero posterior y el prognatismo bucal se relaciona con cráneos oblicuos. Así mismo, la alteración de la forma natural de la cabeza implica la redistribución del peso, lo cual afecta la postura de la cabeza y el cuello (Tiesler 2014). Todo esto seguramente fue también percibido como rasgos de la identidad.

Huellas de presión en el frontal: Se refiere a zonas aplanadas en el frontal, que se observan con mayor facilidad en las vistas laterales y que son claramente palpables (v.g. Fig. 2A y 2B, vistas laterales en la fila superior). Son producto de la presión ejercida por elementos de los aparatos deformadores, tales como almohadillas o tablillas. Pueden ser una o más y estar localizadas en distintas posiciones. Considerando las posibles variaciones individuales, este rasgo fue registrado como 


\begin{tabular}{|l|l|l|l|l|}
\hline Sitio & Número & Sexo & Edad & Cronología \\
\hline Pernil Alto & 6 & Femenino & Juvenil & Paracas temprano \\
\hline Pernil Alto & $7-1$ & Masculino & Adulto medio & Paracas temprano \\
\hline Pernil Alto & $7-2$ & Masculino & Adulto joven & Paracas temprano \\
\hline Pinchango Alto & 1 & Femenino & Adulto joven & Paracas Tardío \\
\hline Jauranga & 18 & Indeterminado & Niño & Paracas medio \\
\hline Jauranga & 22 & Posiblemente masculino & Adulto medio & Paracas Tardío \\
\hline Jauranga & 26 & Masculino & Adulto joven & Paracas Tardío \\
\hline Jauranga & 35 & Masculino & Adulto joven & Paracas Tardío \\
\hline Jauranga & 53 & Femenino & Adulto mayor & Paracas Tardío \\
\hline Jauranga & $64-3$ & Femenino & Adulto & Paracas Tardío \\
\hline Jauranga & $64-4$ & Masculino & Adulto medio & Paracas Tardío \\
\hline Jauranga & $66-3$ & Indeterminado & Adolescente & Paracas Tardío \\
\hline Jauranga & $66-2$ & Posiblemente masculino & Adulto joven & Paracas Tardío \\
\hline Jauranga & $67-3$ & Indeterminado & Adulto mayor & Paracas Tardío \\
\hline Jauranga & 74 & Indeterminado & Niño & Paracas Tardío \\
\hline Collanco & $5339-3$ & Indeterminado & Adolescente & Transicional \\
\hline Estaquería & 3322 & Indeterminado & Infante & Transicional \\
\hline
\end{tabular}

Tabla 1. Muestra de fardos de Wari Kayán.

presente o ausente (concavidad de la línea vertical del frontal de Weiss 1961; efectos de presión en el frontal de Hoshower et al. 1995; aspecto anterior de Buikstra y Ubelaker 1994).

Morrillo frontal: Se trata de la convexidad que se ubica en la parte superior del frontal, siguiendo el trazo de la sutura coronal y que suele ser más marcada en la zona bregmática. En una perspectiva lateral se observa como una prominencia en la parte alta de la frente (v.g. Figs. 2A-2E, vistas laterales en la fila superior). Como en el caso anterior, este rasgo fue registrado como presente o ausente. Weiss (1961: 50) lo interpreta como una consecuencia de la combinación de la presión en el frontal y en la región retro-coronal, con almohadillas en el primer caso; y amarres o cintas, en el segundo. Por su parte, Tiesler (2014) considera que este rasgo y el siguiente son producto del uso de aparatos deformadores muy ajustados tiempo después del cierre de las fontanelas ${ }^{4}$ saliente antibregmática o morrillo de Weiss 1961; elevación bregmática de Buikstra y Ubelaker 1994).

Surco retro coronal: Refiere a una convexidad que se ubica en los parietales, siguiendo el trazo de la sutura coronal y más marcada en las partes laterales. Es difícil de registrar en fotografías o radiografías, y debe hacerse a través de la palpación. Se registró su presencia o ausencia. Weiss (1961: 50) lo interpreta como producto de la presión ejercida por algún elemento, tipo amarre o cinta del aparato deformador, en tanto que Tiesler (2014) le da la misma etiología que al rasgo anterior (surco o gotiera post bregmática de Weiss 1961; constricción poscoronal de Hoshower et al. 1995; depresión poscoronal de Buikstra y Ubelaker 1994).

Surco supra mastoideo: Se trata de la depresión que se observa en la vista posterior de los cráneos, y que afecta la parte inferior de la escama del occipital y lateral de los temporales, por encima de las apófisis mastoideas (v.g. Fig. 7, columna E; Jauranga 26). ${ }^{5}$ También, se registró su presencia o ausencia. Sería causada por un elemento del amarre y Weiss (1961) menciona que es muy frecuente en las modificaciones por llautu con aplanamiento posterior del subgrupo Paracas (cintura supra mastoidea de Weiss 1961). 


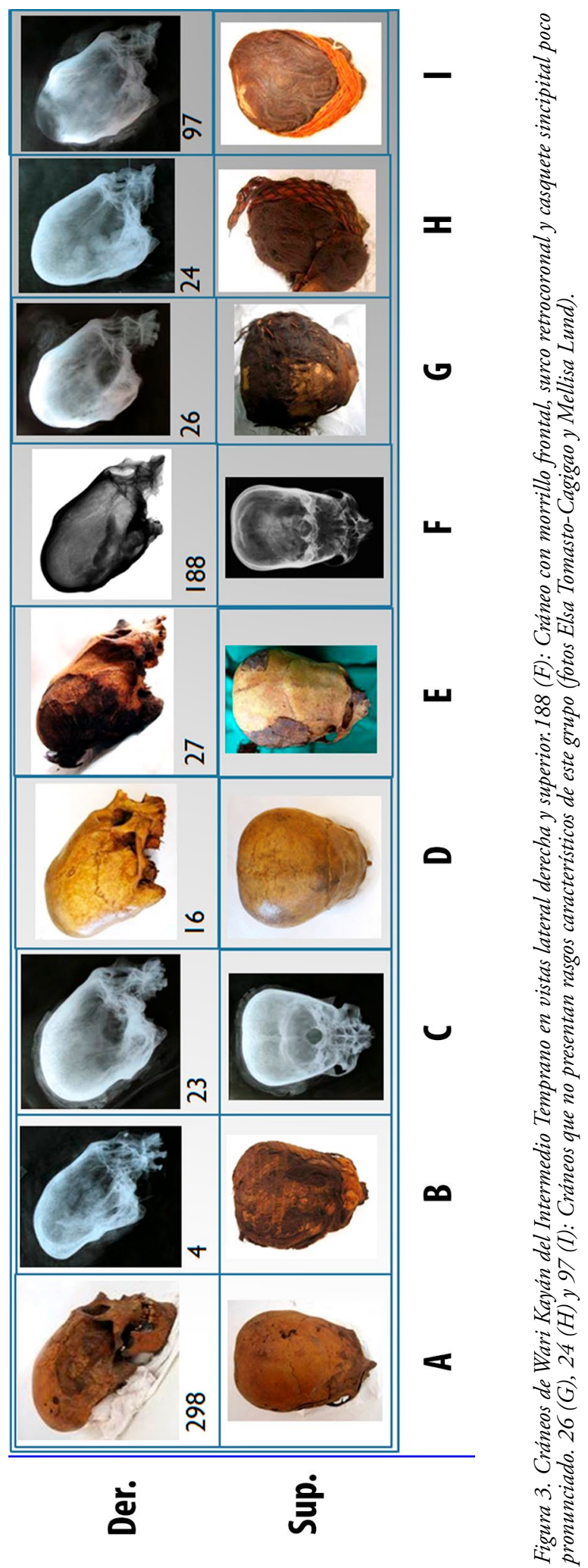




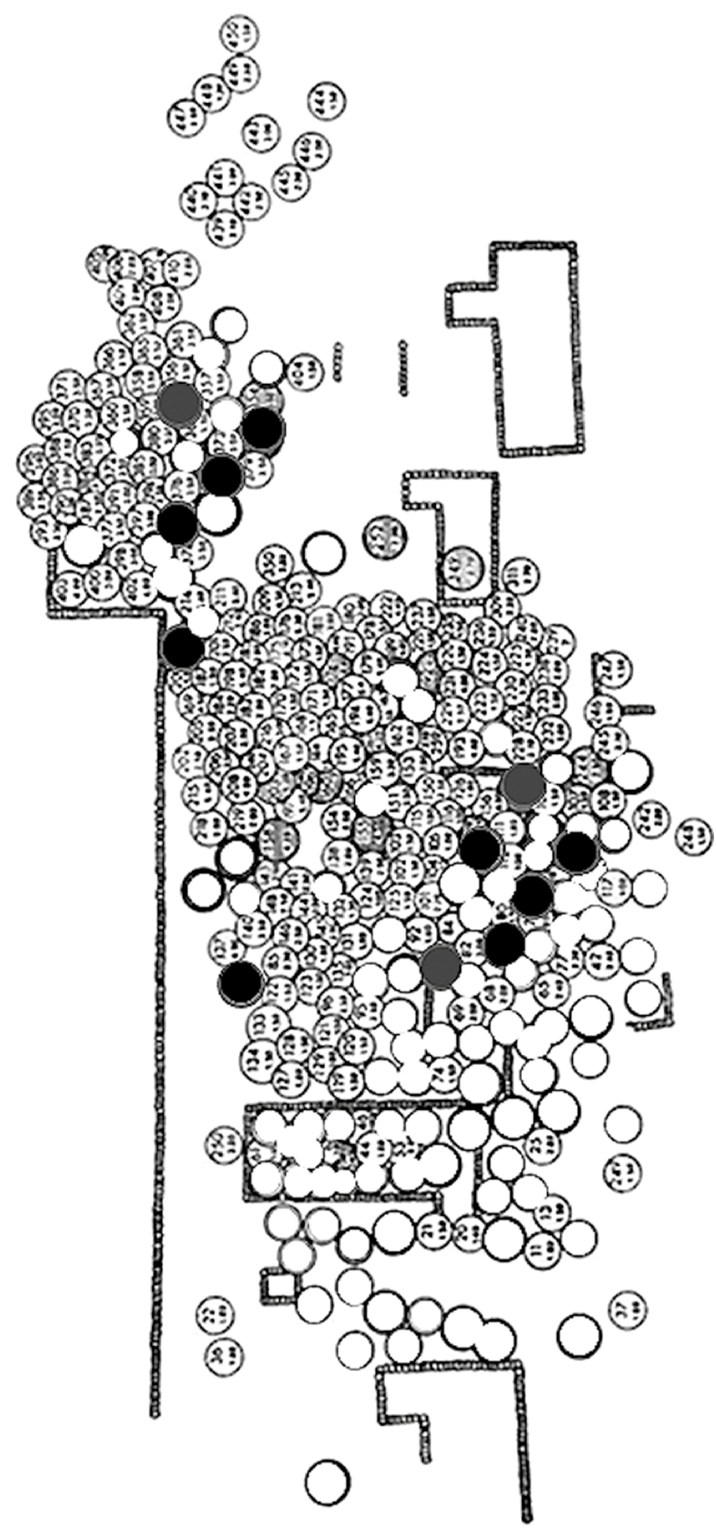

Figura 4. Distribución de fardos estudiados del Horizonte Temprano en el cementerio de Wari Kayán. Los tres puntos grises corresponden a los cráneos que tienen menos rasgos en común con los demás (redibujado de Tello y Mejía Xesspe 1979).

Huellas de presión en la región posterior: Corresponden a depresiones en la escama del occipital $\mathrm{y}$ en la parte posterior de los parietales, que se observan en vista lateral y posterior, y que son claramente palpables (v.g. Figura 3: B, vista lateral en la fila superior). Se registraron como presentes o ausentes. Son producto de la presión ejercida por elementos de los aparatos deformadores, tales como almohadillas o tablillas. Pueden ser una o más y estar localizadas en distintas posiciones (Occipital de Hoshower et al. 1995, aspecto posterior de Buikstra y Ubelaker 1994).

Forma del vértex: Se refiere a la morfología del cráneo vista desde la parte superior. En los cráneos observados, puede ser circular (Figs. 2A, 2C, fila inferior), ovalada (Fig. 2K, fila inferior) 

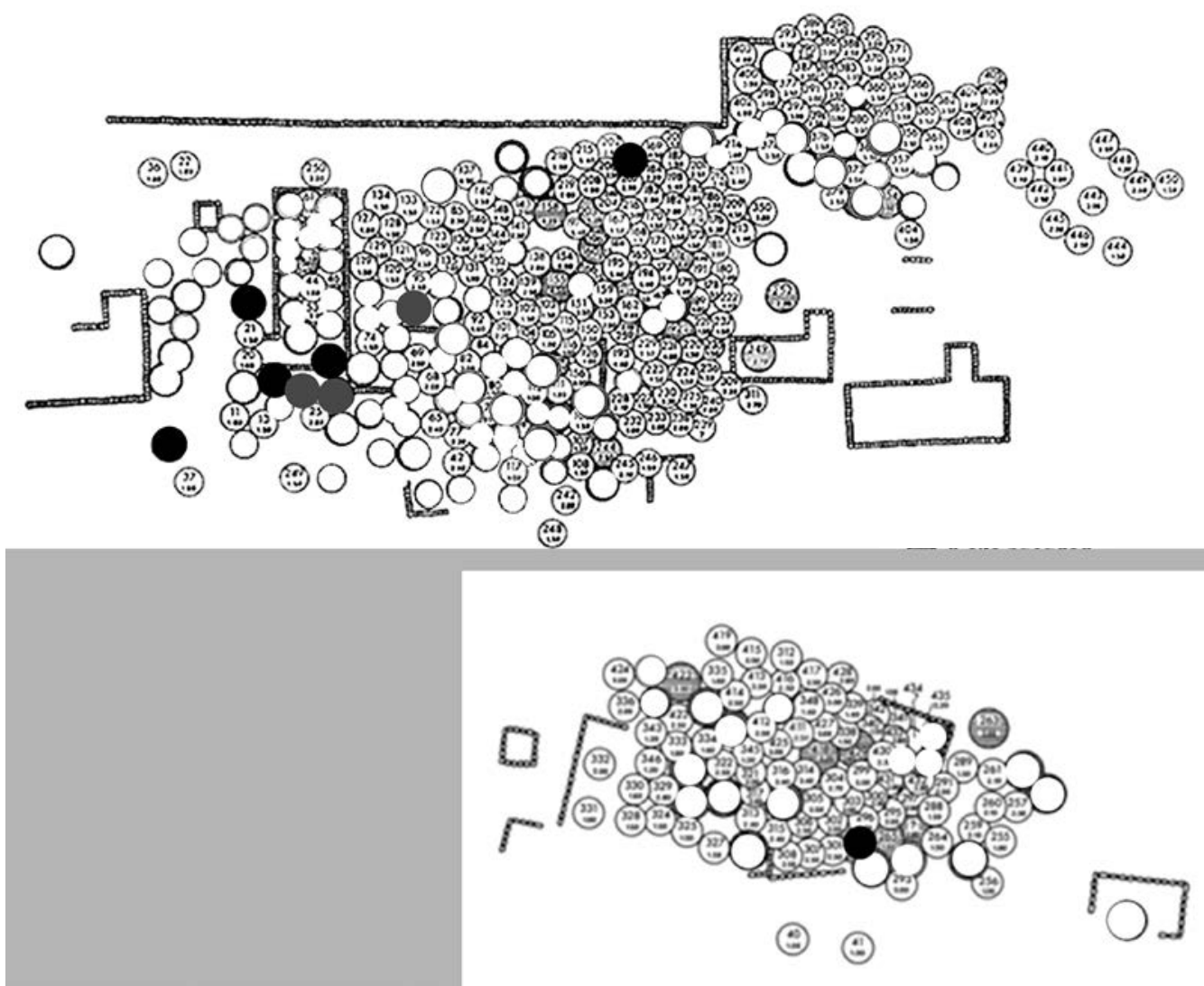

Figura 5. Distribución de fardos estudiados del Intermedio Temprano en el cementerio de Wari Kayán. Los tres puntos grises corresponden a los cráneos que tienen menos rasgos en común con los demás (redibujado de Tello y Mejía Xesspe 1979).

o acorazonada (Fig. 3D, fila inferior). Weiss (1961) denomina casquete sincipital a la forma que caracteriza a las cabezas puntiagudas en su parte superior (v.g. Fig. 2A, vista lateral en la fila superior), que sería consecuencia de una manera particular de amarrar el aparato deformador. $\mathrm{Al}$ respecto, sugiere que esta sería la cabeza en forma de mortero que describen algunos cronistas como característica de la nobleza inca.

Inclinación de la bóveda craneal: Alude al ángulo de inclinación del frontal y el occipital en relación con el plano de Frankfort en las vistas laterales. Corresponde a las formas erecta y oblicua de Imbelloni (Dembo e Imbelloni 1968). Weiss (1961) se refirió a esta característica al notar la existencia de formas «echadas». Como veremos más adelante, la mayoría de cráneos de esta colección son oblicuos e inicialmente los registramos como tales. No obstante, al realizar la seriación de las formas, encontramos que existen grados de inclinación que solo se perciben al comparar un conjunto de cráneos con el otro (v.g., compárense las Figs. $2 \mathrm{E}$ y $3 \mathrm{~F}$ en sus vistas laterales). ${ }^{6}$

\section{Resultados}

En la muestra de Wari Kayan, de los 12 individuos clasificados en las fases finales del Horizonte Temprano, nueve (Figs. 2A-2I) tenían la bóveda craneal alta y angosta, con el vértex de forma redondeada y puntiaguda, (casquete sincipital de Weiss), huella de presión en el frontal, morrillo 
frontal y surco retro coronal. La forma de estos nueve cráneos es en general homogénea, aun cuando existen ligeras variaciones en el grado de manifestación de los rasgos. Esta variabilidad puede explicarse por el desarrollo particular de cada individuo. Por otra parte, en relación con la inclinación de la bóveda, si bien estos cráneos se pueden clasificar como oblicuos en términos de Imbelloni, en general tienen una tendencia más erecta o son menos «echados» que los cráneos del Intermedio Temprano o transicionales, que serán descritos más adelante.

De los tres cráneos restantes correspondientes a este grupo temprano, dos (Figs. 2J, 2K, vista lateral derecha en la fila superior) también tienen la bóveda craneal alta y con tendencia erecta, el vértex puntiagudo, casquete sincipital, huella frontal, morrillo frontal y surco retro coronal muy marcados. Sin embargo, a diferencia de los nueve cráneos descritos anteriormente, estos dos no tienen el vértex redondeado, sino ovalado o acorazonado, y la bóveda es ancha y no angosta (Figs. 2J, 2K, vista superior en la fila inferior). El último cráneo de este grupo (Fig. 2L) se diferencia de los demás por no presentar casquete sincipital, huella frontal, morrillo frontal, ni surco retro coronal, y por tener el vértex de forma acorazonada y no redonda. En conjunto, este cráneo se parece más a los del Intermedio Temprano, que describiremos más adelante. Es importante mencionar que este es uno de los contextos en que no hubo coincidencia entre el fechado y el estilo predominante en los textiles.

En cuanto a la distribución por sexo y posible categoría social, en este grupo, encontramos tanto hombres como mujeres que fueron enterrados en fardos de primera, segunda y tercera categorías, según la clasificación de Tello ${ }^{7}$ (Tello y Mejía Xesspe 1979). Por otra parte, la distribución de estos 12 contextos en el cementerio de Wari Kayán no muestra ningún patrón (Fig. 4). Comparando estas formas craneales con las clasificaciones realizadas anteriormente, encontramos que podrían incluirse en los tipos Natchez y Cabeza Larga de Weiss.

Con respecto a los nueve individuos clasificados en el Intermedio Temprano o Período Transicional, seis son muy similares entre sí y diferentes de los individuos más tempranos (Figs. 3A-3F). Estos seis cráneos también tienen la bóveda craneal alta, pero ya no angosta sino ancha y más inclinada hacia atrás que los cráneos del Horizonte Temprano (compárense con las Figs. 2A-2E). En ellos, la huella de presión posterior está localizada en un punto más bajo que en los cráneos más tempranos, es decir, entre el Lambda y el Inion. El vértex, por otra parte, no es redondeado, sino de forma ovalada o acorazonada (Figs. 3A-3F, vista superior en la fila inferior). En cinco de ellos (Figs. 3A-3E), no se percibe la huella frontal o esta es muy sutil, y no presentan morrillo frontal, surco retro coronal ni casquete sincipital, mientras que el sexto cráneo (Fig. 3F) sí presenta estos rasgos.

En cuanto a los tres cráneos restantes de este grupo transicional (Figs. 3E-3I), se parecen más a los cráneos tempranos al mostrar inclinación menos pronunciada, huella de presión y morrillo frontales, surco retro coronal y casquete sincipital. Cabe indicar que uno de estos cráneos corresponde a un contexto en que no hubo coincidencia entre el fechado y el estilo predominante en los textiles.

En cuanto a la distribución por sexo y posible categoría social, en este grupo, tenemos solo hombres que fueron enterrados en fardos de las tres categorías. En relación con su distribución en el cementerio, la mayoría están concentrados en un solo sector, pero la existencia de dos contextos alejados sugiere que la distribución podría ser más amplia y aleatoria, como en el caso de los individuos tempranos (Fig. 5). Las formas craneales podrían incluirse en los tipos Necrópolis de Weiss o tabular cilíndrico de Yépez.

El estudio de los cráneos de los valles de Palpa no pudo hacerse con el mismo detalle que los cráneos de Wari Kayan porque solo tres están completos, en tanto que los demás fueron reconstruidos en mayor o menor medida. Los tres cráneos completos (Fig. 6) corresponden a períodos distintos: Paracas Temprano (Fig. 6A), Paracas Tardío (Fig. 6B) y Transicional (Fig. 6C). No obstante, los tres son muy parecidos entre sí y distintos de los de Wari Kayan: los tres tienen la bóveda ancha y baja y el vértex acorazonado, a pesar de que existen ligeras diferencias en la manifestación de las huellas de presión. Estos cráneos corresponden grosso modo al tipo Cavernas de Weiss o al Cuneiforme de Yépez. 


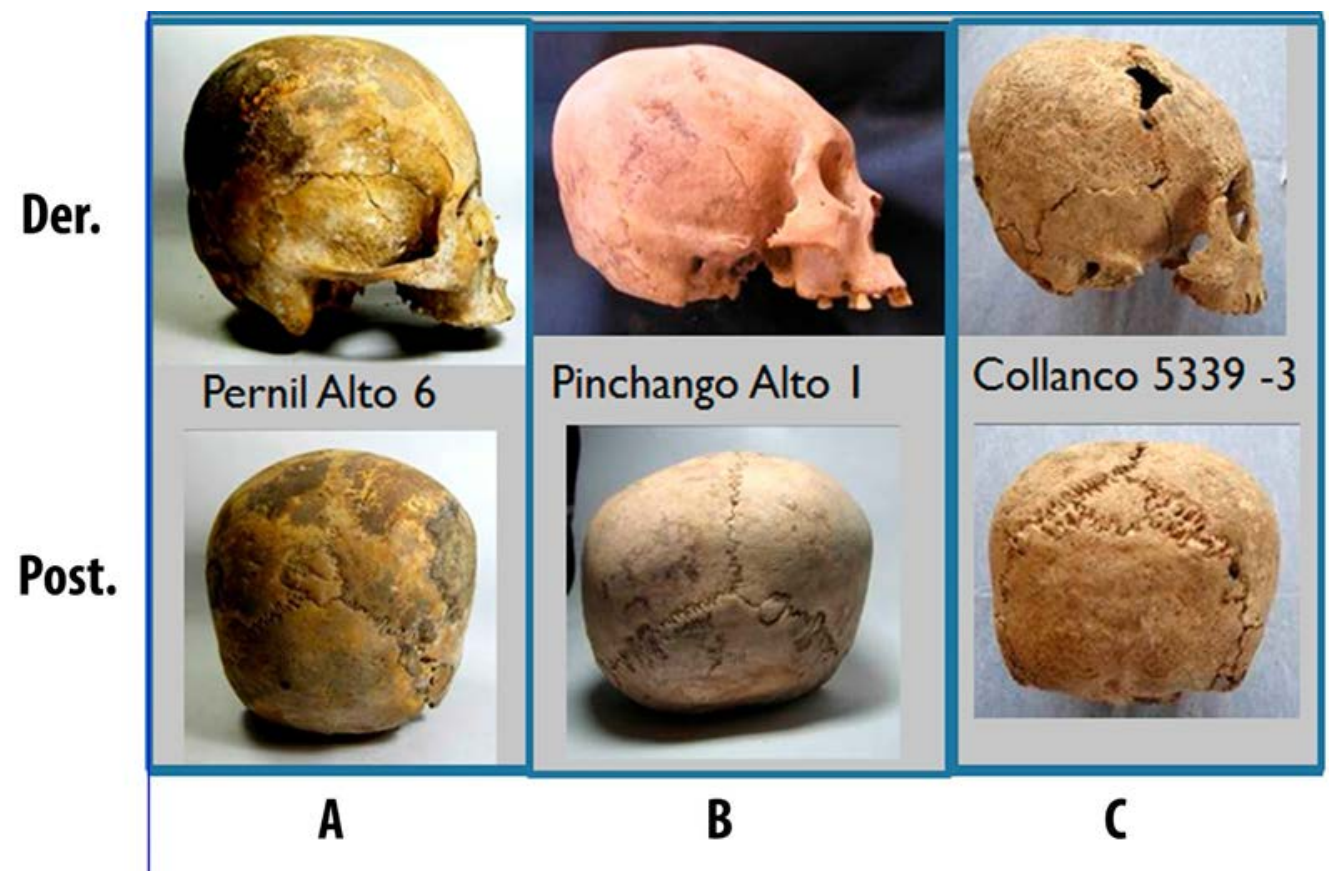

Figura 6. Cráneos enteros de los valles de Palpa en vistas lateral derecha y posterior. Pernil Alto 6 (A): Paracas Temprano. Pinchango Alto 1 (B): Paracas Tardio. Collanco 5339 - 3 (C): Transicional

En los cráneos incompletos de Palpa, también se pudieron observar algunos rasgos. De esta manera, un total de 13 cráneos correspondientes a los tres períodos pudieron ser clasificados de acuerdo con la forma general de la bóveda: la mayoría de ellos (10) tienen la bóveda ancha y baja (Figs. 7A-7D, vista posterior en la fila inferior), y los tres restantes la tienen ligeramente alta, sin llegar a ser similares a los de la península (Fig. 7E, fila inferior). Igualmente, 12 cráneos de los tres períodos pudieron ser clasificados de acuerdo con la forma del vértex: 10 tienen forma acorazonada (Figs. 7A-7C, vista superior en la fila del medio); y solo dos, formas más redondeadas (Figs. 7D, $7 \mathrm{E}$, vista superior en la fila del medio). Finalmente, 14 cráneos pudieron ser observados en vista lateral y delantera. De ellos, 11 no tenían morrillo frontal ni surco retro coronal (Figs. 7A-7C, 7E, vista lateral derecha en la fila superior), dos presentaban estos rasgos en forma muy leve (Fig. 7:D, fila superior) y solo uno los tenía muy claramente definidos.

De esta manera, y sumando los rasgos observados en las normas posterior, superior y laterales, confirmamos que la mayoría de los cráneos de la muestra de Palpa son muy distintos de los cráneos de Wari Kayán, con preponderancia de las bóvedas anchas y bajas, y con el vértex de forma acorazonada. Solo tres cráneos (dos paracas tardío y uno transicional) presentan rasgos, tales como bóvedas más altas, morrillo frontal y surco retro coronal, que sugieren que podrían ser parecidos a los de Wari Kayán, aunque el grado de fragmentación no permite asegurarlo.

En resumen, encontramos que, en esta muestra, la mayoría de cráneos de la península que estaban asociados a textiles clasificados como Horizonte Temprano son alargados, ligeramente inclinados hacia atrás, angostos, con el vértex redondeado y puntiagudo, y con huella frontal, surco retro coronal y morrillo frontal claramente marcados (Figs. 2A-2I). Por otra parte, los cráneos asociados a textiles del Intermedio Temprano son en su mayoría más inclinados hacia atrás o "echados», más anchos, con el vértex en forma de corazón y sin huellas de los aperos en la parte frontal, particularmente sin morrillo frontal ni surco retro coronal. Finalmente, los cráneos de Palpa tienen bóveda baja y ancha, y no muestran huellas claras de los aperos en la parte frontal. 


\section{Discusión y conclusiones}

En el presente ensayo de clasificación de los cráneos modificados paracas, hemos encontrado grupos morfológicos mayoritarios y variantes que se alejan en mayor o menor medida del prototipo. Estos grupos y variantes no son muy distintos de los que han sido identificados en propuestas tipológicas anteriores. Sin embargo, al considerar el contexto como componente fundamental del análisis, podemos proponer cuáles serían los rasgos más significativos de las formas craneales, a nivel social o grupal, y cuáles podrían ser producto de características propias de cada individuo, o de errores o accidentes durante el proceso de remodelación en la infancia. Por otra parte, si bien todavía falta mucho camino para conocer las razones que estuvieron detrás de la práctica de la modificación craneal en el mundo paracas, hemos empezado a armar el rompecabezas y podemos señalar líneas de investigación a futuro en este campo que permitan orientar mejor los estudios.

Un primer punto que debemos resaltar es la necesidad de dirigir las observaciones hacia el aspecto general del cráneo, que podría haber sido percibido por otros individuos contemporáneos como un marcador de identidad, más que a tratar de hacer encajar los cráneos en tipologías generales. Tanto los cráneos del Horizonte Temprano como los del Intermedio Temprano de Wari Kayán pueden clasificarse como tabulares oblicuos o pseudocirculares; sin embargo, hemos visto que la forma del vértex, el grado de inclinación de la bóveda y los rasgos en la parte superior de los frontales los convierten en formas completamente diferenciables en los huesos y, seguramente, también en vida, más aún si consideramos además los cambios en el aspecto de la cara que pueden ocurrir en asociación a la modificación de la bóveda, descritos por Tiesler (2014): postura de la cabeza y el cuello, cráneos extremadamente alargados relacionados con rasgos saltones, rasgos faciales aplanados relacionados con la modificación antero posterior y prognatismo bucal relacionado con cráneos oblicuos. En relación con esto y respecto a la posibilidad de que la forma del vértex pudiera haber sido un rasgo altamente visible y fácilmente percibido por otros en vida, resulta pertinente la observación planteada por Betanzos durante los primeros años de la Colonia: "[...] los orejones dél, [que] eran los señores y los que lo habian de ser en toda la tierra, tenían tusado el cabello y aguzadas las cabezas para arriba, por la cual señal habian de ser conocidos por toda la tierra [...]» (2008 [1880], el énfasis es nuestro).

Otro aspecto por discutir es el de la posible explicación de las diferencias observadas entre los cráneos de Wari Kayán. No es un misterio el que su causa primordial esté en los elementos de los aparatos deformadores empleados y la manera como estos eran colocados, amarrados y ajustados, y en el caso de los morrillos frontales y surcos retro coronales marcados, posiblemente, en el hecho de continuar con el uso de deformadores ajustados hasta una edad más allá del tiempo de cierre de las fontanelas. Es decir, es evidente que la causa de estas diferencias está en las prácticas culturalmente aprendidas y grupalmente específicas para la modificación del cráneo. Así mismo, las variantes menores que percibimos como rasgos presentes, pero menos pronunciados, pueden explicarse como características individuales o prácticas menos cuidadosas dentro del grupo. Por otro lado, la presencia minoritaria de formas completamente diferentes en un conjunto puede entenderse en el contexto de grupos de personas que no están estrictamente cerrados y en los que existe un cierto grado de movimiento intergrupal.

Queda, sin embargo, abierta la pregunta de la conformación de estos grupos. El cambio de forma craneal predominante en Wari Kayán entre el Horizonte Temprano y el Intermedio Temprano podría entenderse simplemente como un cambio temporal o generacional. No obstante, considerando la presencia de formas «tardías» en el grupo «temprano» y viceversa, y teniendo en cuenta además el contexto general de creciente interacción de poblaciones que llamamos topará con poblaciones que llamamos "paracas» en la costa sur, y su punto de convergencia en la península de Paracas, es posible pensar más bien que este cambio en las formas de cabeza predominantes revelaría grupos de poder en competencia. En este sentido, es importante recordar que la muestra analizada procede de los fardos más grandes, es decir, de los que fueron objeto de más procedimientos de envoltura y reenvoltura en el contexto de rituales mortuorios extendidos, y que, por tanto, fueron percibidos en algún momento como personajes importantes o quizás ancestros poderosos. 


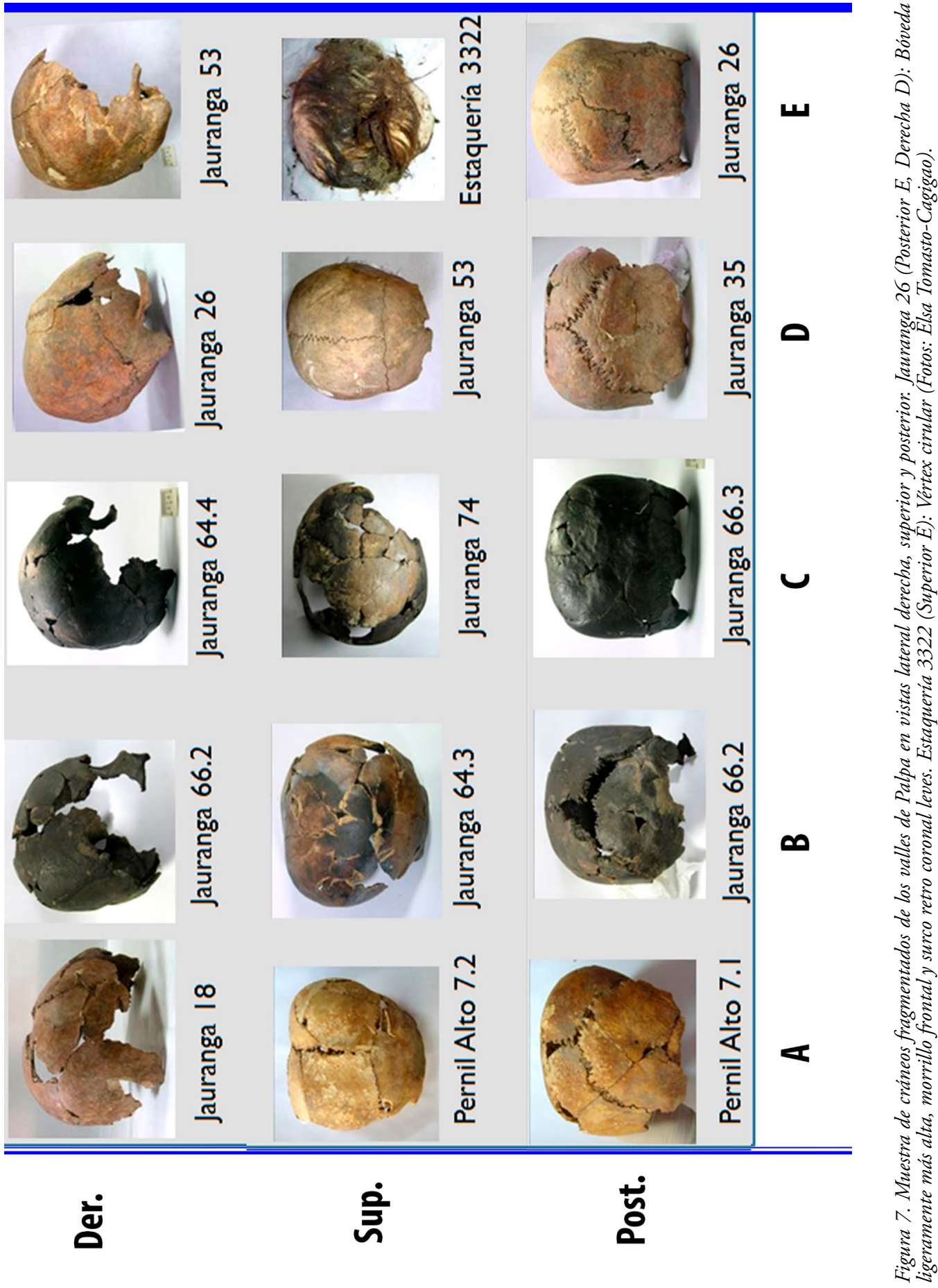




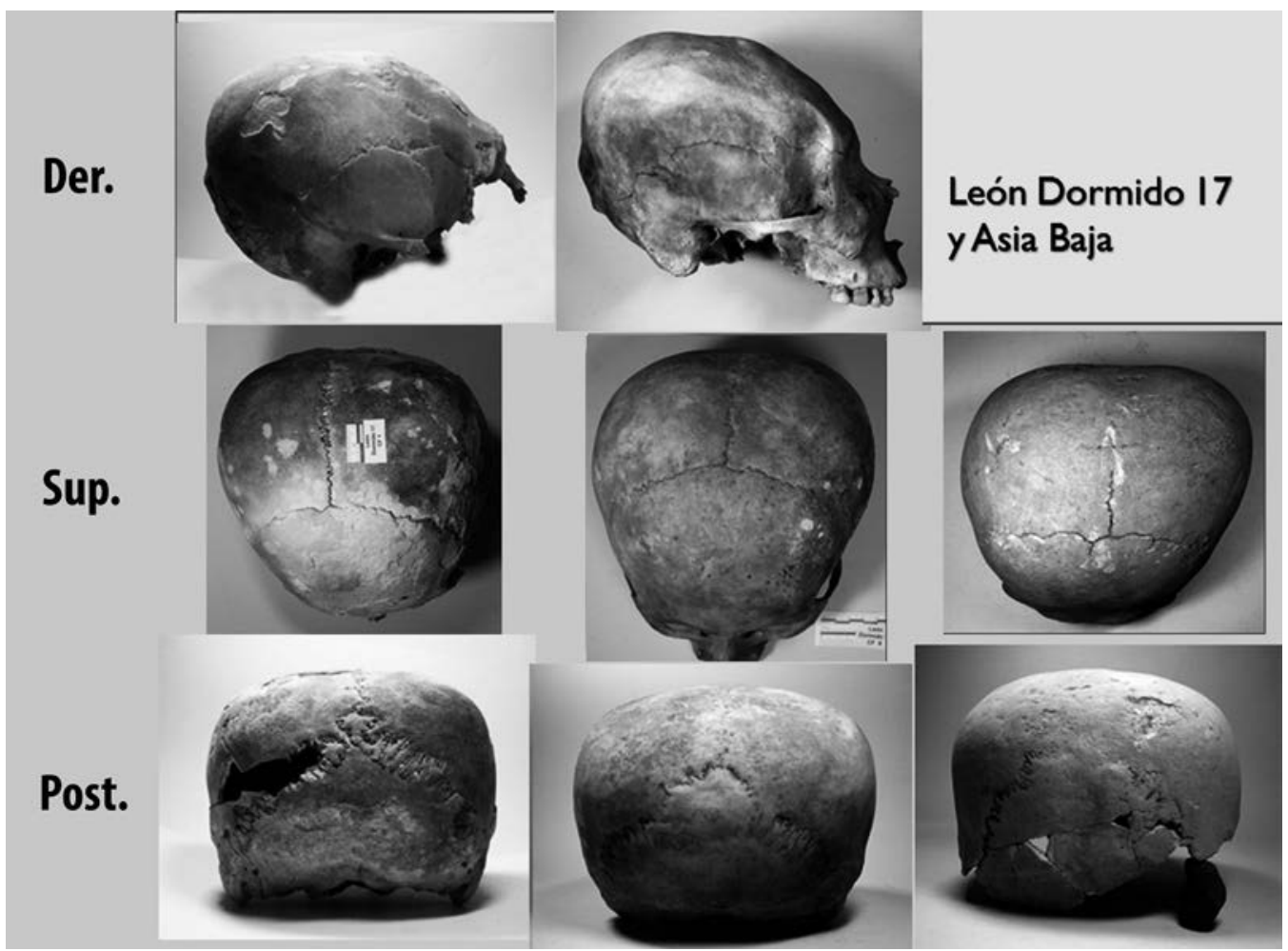

Figura 8. Cráneos de León Dormido 17 y Asia Baja en vistas derecha, superior y posterior (Fotos: Elsa TomastoCagigao).

Para explorar mejor estas posibilidades y poder dar una respuesta, sería necesario investigar una muestra más grande en Wari Kayan, tomando como guía los rasgos morfológicos que han revelado ser significativos en este estudio, y, de igual manera, ampliar la investigación hacia otros grupos contemporáneos en regiones al norte y al sur de la península. En este sentido, resulta muy informativo el análisis realizado en la muestra de los valles de Palpa, que demuestra que las formas craneales predominantes en esta región son muy diferentes a las observadas en la península y son consistentes a lo largo del tiempo. La presencia de unos pocos cráneos de formas parecidas a los de Wari Kayán estaría revelando contactos y movimientos poblacionales reducidos.

Considerando la marcada diferencia de forma entre los cráneos de Wari Kayán y los de Palpa, podría plantearse también que es una diferenciación regional, similar a la que encontró Blom (1999) en el área de influencia Tiwanaku: cráneos bajos y anchos en el sur, a lo largo de toda la secuencia Paracas, y cráneos altos en la Península, por lo menos, en lo que corresponde al final del Horizonte Temprano y al Período Transicional. ¿Esto se relaciona con la dicotomía Paracas-Topará? ¿Podría ser que los cráneos altos estén relacionados con lo Topará, y los cráneos anchos y bajos con lo Paracas? Considerando que Weiss llamó «Cavernas» a los cráneos anchos y bajos de la península, haciendo referencia a un conjunto de rasgos que tradicionalmente se han considerado Paracas esta podría ser una posibilidad. Creemos que, en este caso, como en la cerámica y los textiles, el haber llamado «Paracas» a todos los componentes culturales de la península ha complicado la discusión y hace falta conocer más de las características morfológicas de los cráneos de los habitantes de los valles más norteños. En este sentido, en una revisión de fotografías de una pequeña muestra de época Ocucaje Medio en el sitio de León Dormido, y de una época indeterminada del Horizonte Temprano en Asia Baja, ambos en Cañete (Bautista 2011), encontramos que la forma de los cráneos es similar a los de Palpa y no a los de Wari Kayán (Fig. 8). Esto sugeriría que los cráneos de los individuos 
enterrados en Wari Kayán son diferentes de mucho de lo que hay alrededor, pero las muestras son todavía muy pequeñas para llegar a una conclusión.

Todo esto nos lleva a la recomendación final de que es muy importante mirar con más cuidado el material antropológico y, en el caso de las modificaciones craneales de la costa sur, no quedarse en las tipologías generales, sino fijarse en detalles como los que han sido propuestos en este artículo. Artefactos como la cerámica y los textiles se pueden mover muy fácilmente, pero las personas pueden ser más estables en relación con el grupo. En el caso de las modificaciones craneales, estas son marcadores indelebles realizados en el grupo de origen y esta diferencia es muy importante, sobre todo, en etapas de grandes cambios, como el final del Período Formativo.

\section{Agradecimientos}

Este estudio fue posible gracias a las facilidades de investigación otorgadas por el Museo Nacional de Arqueología, Antropología e Historia del Perú (MNAAHP), el Museo Regional de Ica (MRI), el Museo Inka de la Universidad San Antonio Abad del Cusco, el Museo Peabody de Arqueología y Etnología de la Universidad de Harvard y el Museo de Historia Natural de Nueva York, así como por el apoyo constante de las personas que trabajan en ellos. El acceso a las colecciones procedentes de las colecciones de Palpa fue facilitado por Markus Reindel y Johny Isla. El acceso a los materiales de León Dormido fue autorizado por la empresa Trashumantes S.A.C. y su directora, Lucía Balbuena. El apoyo económico para estas investigaciones fue brindado por el Programa de Arqueología de la National Science Foundation de Estados Unidos, el Instituto Arqueológico Alemán, la Fundación Suiza Liechtenstein para Investigaciones Arqueológicas en el Exterior, el Ministerio de Cultura de Alemania y la Empresa Transportadora de Gas del Perú - TGP. Las radiografías fueron tomadas en el Departamento de Metales del MNAAHP, en el Centro Radiológico Virgen del Carmen de Cusco, en el Hospital Mount Auburn en Cambridge, y con el apoyo de Jerry Conlogue y Ron Becket en Nueva York. Los fechados radiocarbónicos se realizaron en los laboratorios Beta Analytic y fueron interpretados por Ingmar Unkel. Finalmente, esta investigación no hubiera sido posible sin el inagotable entusiasmo y constante apoyo de Ann Peters.

\section{Notas}

${ }^{1}$ El trabajo de Lucie Dausse es parte de una tesis doctoral que a la fecha de preparación de este artículo ha sido sustentada, pero todavía no es de acceso público, por lo cual no se hace más comentarios sobre ella en los párrafos siguientes.

${ }^{2}$ Respecto a los problemas para registrar cráneos con peinados y tocados bien conservados, y las posibilidades de estudio mediante radiografías, véase Manríquez et al. (2006).

${ }^{3}$ Nuestra traducción de «Ainsi, au point de vue plus général de la classification des déformation crâniennes, nous devons admettre que le cadre dans lequel, suivant J. Imbelloni, les anthropologistes s'efforent de faire entrer les crânes déformés, est inadéquat. Toute observation minutieuse se heurte à cette difficulté [...] Avec des teres aussi vagues que "tabulaire" ou "antéro-postérieur" et "circulaire", aussi equivoques que "droite" et "oblique", on est amené à groupper des pièces dont l'istoire et même láspect sont tout différent».

${ }^{4}$ «In particular, when the compression is severe and prolonged past fontanelle closure, sutural growth tends to produce compensatory bulging on the margin toward the compressed side and will generate a furrow on the other, unrestricted side» (Tiesler 2014: 43).

${ }^{5}$ En este caso, se trata de una presentación poco marcada del rasgo.

${ }^{6}$ En este sentido, al aplicar este sistema de clasificación a una colección distinta, se recomienda usar las figuras de referencia. 
7 Tello estableció tres categorías de fardos considerando su peso y su tamaño. Sin embargo, más que rangos sociales, estas categorías expresan el número de reenvoltorios realizados en rituales post mortem posiblemente relacionados con la transformación del individuo en ancestro. Hasta qué punto la posibilidad de ser transformado en ancestro se relaciona con un estatus social en vida es un tema que debe ser estudiado y que depende en gran medida de poder tener acceso a los numerosos fardos de Wari Kayán que permanecen sin haber sido estudiados.

\section{REFERENCIAS}

Allison, M., E. Gertzen, J. Munizaga, C. Santoro y G. Focacci

1981 La práctica de la deformación craneana entre los pueblos andinos precolombinos, Chungara 7, 238-260.

Anton, $S$.

1989 Intentional cranial vault deformation and induced changes of the cranial base and face, American Journal of Physical Anthropology 79, 253-267. https://doi.org/10.1002/ajpa.1330790213

Aponte, D.

2013 Ciclo de vida y modificaciones corporales en Paracas Necrópolis, Paracas (Catálogo de la exposición), 41-49, Museo Nacional de Arqueología, Antropología e Historia del Perú/Ministerio de Cultura, Lima.

Bautista, L.

2011 Informe del proyecto de rescate arqueológico de la ampliación del sistema de transporte por ductos de gas natural: sector Pampa Melchorita - Lurín (Loop Costa), manuscrito.

Betanzos, J. de

2008 Suma y narración de los Incas, que los indios llamaron Capaccuna, que fueron señores de la ciudad del Cuzco [1880] $y$ de todo lo a ella subjeto, The Project Gutenberg EBook \#25705.

Bolender, C., B. Hanzel y J. C. Turlot

1978 Analyses multidimensionnelles du profil cranio-facial précolombien et Péruvien contemporain, Revue Orthopédie Dento Faciale 12 (4), 397-421. https://doi.org/10.1051/odf/1978021

Blom, D.

1999 Tiwanaku regional interaction and social identity: a bioarchaeological approach, tesis de doctorado, Departamento de Antropología, Universidad de Chicago, Chicago.

Buikstra, J. y D. Ubelaker (eds.)

1994 Standards for data collection from human skeletal remains, Arkansas Archaeological Survey Research Series 44, Arkansas Archaeological Survey, Fayetteville.

Dausse, L.

2015 Étude des déformations crâniennes intentionnelles dans la culture Paracas (800 avant - 100 après J.C.): Les contextes funéraires de Cerro Colorado, côte sud du Pérou, tesis de doctorado, Departamento de Arqueología, Universidad Paris I Panthéon Sorbonne, París.

Dembo, A. y J. Imbelloni

1938. Deformaciones intencionales del cráneo de carácter étnico, J. Anesi, Buenos Aires,

Deshayes, M. J.

2005 Mécanique crânienne et morphogenèse mandibulaire. Étude des effets d'un «forçage» par déformation intentionnelle (1 re partie), Biometrie Humaine et Antropologie 23,1-2, 83-93.

DiGangi, E. A., J. D. Bethard, E. H. Kimmerle y L. W. Konigsberg

2009 A new method for estimating age-at-death from the first rib, American Journal of Physical Anthropology 138, 164-176. https://doi.org/10.1002/ajpa.20916

Fehren-Schmitz, L. y E. Tomasto-Cagigao

2012 Analysis of ancient mitochondrial DNA from Paracas individuals, ponencia presentada en simposio Paracas-Nasca: una época «transicional» del Formativo Tardío, costa sur de los Andes Centrales, 9-12 de agosto, Ica. 
Fehren-Schmitz, L., B. Llamas, E. Tomasto-Cagigao y W. Haak

2013 El ADN antiguo y la historia del poblamiento temprano de la parte oeste de Sudamérica: lo que hemos aprendido y hacia dónde vamos, en: P. Kaulicke y T. D. Dillehay (eds.), Tradiciones andinas tempranas: tecnología, cultura y medioambiente, Boletín de Arqueología PUCP 15, 17-41.

Hoshower, L., J. E. Buikstra, P. S. Goldstein y A. D. Webster

1995 Artificial cranial deformation at the Omo M10 Site: a Tiwanaku complex from the Moquegua Valley, Peru, Latin American Antiquity 6 (2), 145-164. https://doi.org/10.2307/972149

Imbelloni, J.

1925 Deformaciones intencionales del cráneo en Sudamérica: polígonos craneanos aberrantes, Revista del Museo de La Plata 28, 329-407.

Iscan, M.Y., S. R. Loth y R. K.Wrigth

1984 Age estimation from the rib by phase analysis: white males, Journal of Forensic Sciences 29, 1094-1104. https://doi.org/10.1520/jfs11776j

Iscan, M. Y. y S. R. Loth

1986 Determination of age from the sternal rib in white females: a test of the phase method, Journal of Forensic Sciences 31, 990-999

Isla, J.

2009 From hunters to regional lords: funerary practices in Palpa-Peru, en: M. Reindel y G. Wagner (eds.), New Technologies for Archaeology, 119-140. https://doi.org/10.1007/978-3-540-87438-6_8

Jiménez, $P$.

2011 Deformación craneal antero-posterior intencionada: variaciones métricas maxilares, tesis de doctorado, Facultad de Medicina y Odontología, Universidad de Santiago de Compostela, Santiago de Compostela.

Lovejoy, O., R. Meindl, R. Pryzbeck y R. Mensforth

1985 Chronological methamorphosis of the auricular surface of the ilium: a new method for the determination of adult skeletal age at death, American Journal of PhysicalAnthropology 68, 15-28. https://doi. org/10.1002/ajpa.1330680103

Manríquez, G., F. E. González-Bergás, J. C. Salinas y O. Espoueys

2006 Deformación intencional del cráneo en poblaciones arqueológicas de Arica, Chile: análisis preliminar de morfometría geométrica con uso de radiografías craneofaciales, Chungara, Revista de Antropología Chilena 38 (1), 13-34. https://doi.org/10.4067/S0717-73562006000100004

Maita, P. y E. Minaya

2014 El trauma en la piel: un análisis paleopatológico de tatuajes Paracas Necrópolis, Revista Jangwa Pana 13, 14-33. https://doi.org/10.21676/16574923.1369

Molina, C. de (del Cuzco)

1947 Ritos y fabulas de los incas, Coleccion Eurindia 14, Editorial Futuro, Buenos Aires.

[1573]

Phenice, T. W.

1969 A newly developed visual method of sexing the os pubis, American Journal of Physical Anthropology 30, 297-301. https://doi.org/10.1002/ajpa.1330300214

Reichlen, P.

1961 La déformation de la têTe au moyen d'appareils de type «vuita-nete» au Pérou et en Malaisie, Travaux de l'Institut Francais d'Études Andines 8, 59-82, Lima.

Scheuer, L. y S. Black

2000 Developmental juvenile osteology, Academic Press, San Diego.

Suchey, J.

1986 Skeletal age standards derived from an extensive multiracial sample of modern Americans, ponencia presentada en la 55 reunión anual de la Asociación Americana de Antropólogos Físicos, Albuquerque.

Tello, J. C. y T. Mejía Xesspe

1979 Paracas. Parte II: Cavernas y Necrópolis, Universidad Nacional Mayor de San Marcos, Lima. 
Tiesler, V.

2014 The bioarchaeology of artificial cranial modifications. New approaches to head shaping and its meanings in precolumbian Mesoamerica and beyond, Springer, New York. https://doi.org/10.1007/978-1-46148760-9

Tomasto-Cagigao, E.

2013 Los Paracas: hablan las momias y los esqueletos, Paracas (Catálogo de la exposición), 67-75, Museo Nacional de Arqueología, Antropología e Historia del Perú/Ministerio de Cultura, Lima.

Tomasto-Cagigao, E., A. Peters, M. Lund y A. Ayarza

2013 Body modification at Paracas Necropolis (South Coast of Peru ca. 2000 BP), en: P. Della Casa y C. Witt (eds.), Tattoos and body modifications in antiquity, Proceedings of the Sessions at the EAA Annual Meetings in The Hague and Oslo, 2010-11, Zurich Studies in Archaeology 9, $49-58$.

Tomasto-Cagigao, E., M. Reindel y J. Isla

2015 Paracas funerary practices in Palpa, South Coast of Peru, en: P. Eeckhout y L. S. Owens (eds.), Funerary practices and models in the Ancient Andes: the return of the living dead, Cambridge University Press, Nueva York.

Tomasto-Cagigao, E., M. Lund, U. García, K. Knudson y G. Lombardi

2016 Análisis de los materiales asociados: restos humanos, Wari Kayan: fardo funerario 298, ochenta y siete años después, Arqueológicas 30, 37-48.

Tomasto-Cagigao, E. y A. Peters (eds.)

e. p. De Paracas a Nasca, interacción y transición: esferas geográficas, prácticas sociales y procesos históricos en la Costa Sur, Colección Actas y Memorias, IFEA, en prensa.

\section{Tommaseo, M. y A. Drusini}

1984 Physical anthropology of two tribal groups of Amazonic Peru (with reference to artificial cranial deformation), Zeitschrift für Morphologie und Anthropologie 74 (3), 315-333.

Torres-Rouff, C.

2003 Shaping identity: cranial vault modification in the pre-Columbian Andes, tesis de doctorado, Departamento de Antropología, Universidad de Santa Bárbara, Santa Bárbara.

Unkel, I., M. Reindel, H. Gorbahn, J. Isla, B. Kromer y V. Sossna

2012 A comprenhensive numerical chronology for the pre-Columbian cultures of the Palpa Valleys, South Coast of Peru, Journal of Archaeological Science 39, 2294-2303. https://doi.org/10.1016/j.jas.2012.02.021

Weiss, P.

1961 Osteología cultural: prácticas cefálicas, segunda parte, Universidad Nacional Mayor de San Marcos, Lima.

Yépez, R.

2006 La práctica cultural de modelar la cabeza en dos culturas andinas del antiguo Perú: Paracas y Chancay. Un estudio de los procesos de significación de la cabeza modelada intencionalmente, tesis de doctorado, Facultad de Filosofía y Letras, Universidad Autónoma de México, México DF.

Zabala, P.

2014 Source compilation on head-shaping practices in Hispanic America, en: Tiesler, V. (ed.), The bioarchaeology of artificial cranial modifications. New approaches to head shaping and its meanings in precolumbian Mesoamerica and Beyond, 99-129, Springer, New York.

Recepción: marzo de 2017 Aceptación: mayo de 2017 